\title{
Desarrollo de Formulado para Teñido Orgánico con Añil
}

Formulated development for Organic Dyeing with Indigo

\author{
José A. González \\ Patricia G. Bernal \\ Delmi Linares \\ Elizabeth M. Crown
}





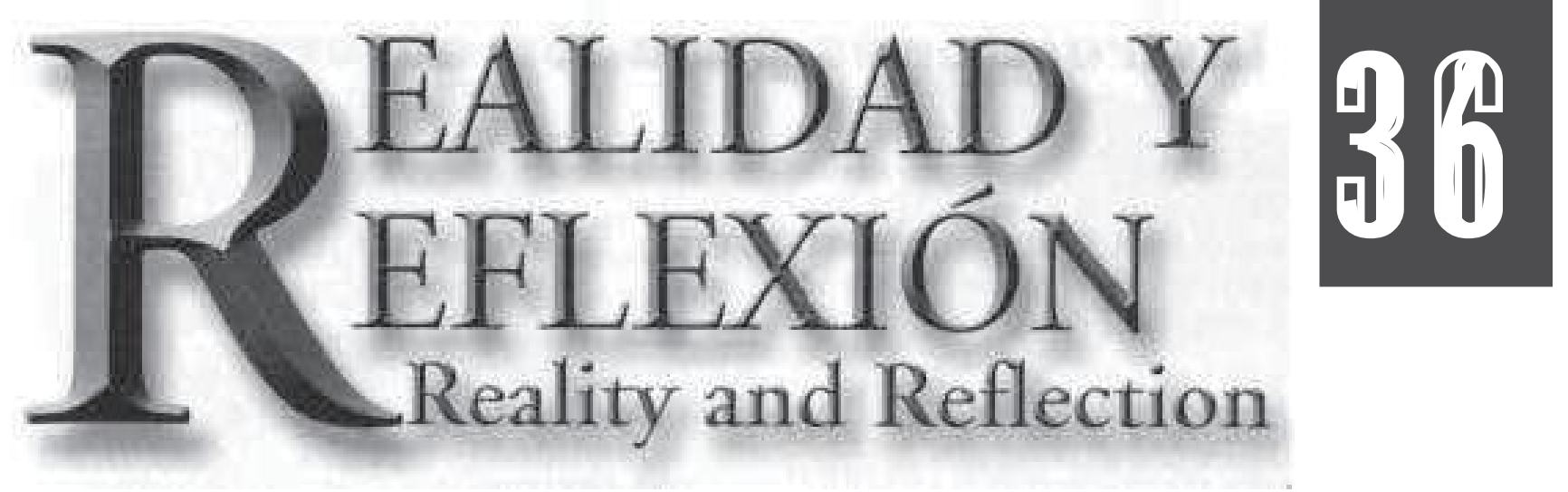

Año 12, No. 36
Year 12, Nr.. $36 \quad$ San Salvador, El Salvador, Centroamérica
San Salvar, El Salvador, Central America
Revista Cuatrimestral

Quarterly J ournal
Septiembre-Diciembre 2012

September-December 2012

\title{
Desarrollo de Formulado para Teñido Orgánico con Añil \\ Formulated development for organic dyeing with Indigo
}

\author{
J osé A. González ${ }^{1}$ \\ Patricia G. Bernal ${ }^{2}$ \\ Delmi Linares ${ }^{2}$ \\ Elizabeth M. Crown ${ }^{3}$
}

\section{Resumen}

Una investigación ha sido conducida para el desarrollo de un formulado orgánico en el teñido con añil de telas de fibras naturales, el cual sea amigable al medio ambiente, y con cero impacto en la salud de los y las teñidoras. La investigación acá reportada encontró que es posible teñir telas de fibras $100 \%$ de algodón con un proceso enteramente orgánico, en donde los componentes del formulado son productos naturales que no causan ningún impacto negativo al medio ambiente, como se detalla a continuación: Afrecho de trigo y melaza como agentes reductores y cal hidratada como agente de control de la alcalinidad. Como se puede observar a continuación, se establecieron los parámetros ideales en la concentración de cada uno de los componentes: tamaño mínimo del baño, orden de mezcla de los componentes, protocolos de los procesos de fermentación y de teñido. Los resultados de teñido demostraron que con el formulado orgánico establecido se pueden teñir telas de $100 \%$ algodón con buena solidez al lavado y al frote, con muy poco sangrado posterior de las telas por excedentes de colorante añil. Descriptores: AÑIL, TINTES Y TEÑIDO, ARTESANIAS TEXTILES, RECURSOS NATURALES, MEDIO AM BIENTE

\section{ABSTRACT}

An investigation has been conducted for the development of an organic formulated in the indigo dyeing of natural fibers, which is friendly to the environment, and with zero impact on health and dyers. The research reported here found that it is possible to dye fiber fabrics $100 \%$ cotton with entirely organic process, where the components of the formulation are natural products that cause no adverse impact to the environment, as follows: wheat bran and reducing agents molasses and hydrated lime agent alkalinity control. As seen below, the ideal parameters were established in the concentration of each of the components: minimum size of the bath, by mixing the components, protocols fermentation processes and dyeing. The results showed that dyeing with established organic formulated dyed fabrics are $100 \%$ cotton with good fastness to washing and rubbing, with very little bleeding after overage fabrics indigo dye. Descriptors: INDIGO, DYES AND DYEING, TEXTILES HANDICRAFTS, NATURAL RESOURCES, ENVIRONM ENT 


\section{Introducción}

La nueva conciencia ecológica en el consumo mundial hacia productos más sustentables en términos sociales, ambientales y de salud, han abierto nuevas oportunidades para el colorante añil como producto natural usado en teñidos de fibras textiles naturales, ya que existe una mayor preocupación de parte de los consumidores por los efectos negativos que pueden causar los colorantes sintéticos y auxiliares.

Los beneficios ecológicos y económicos en el cultivo, extracción y teñido con añil se dan doblemente: los pequeños agricultores pueden obtener ganancias significativas cultivando Xiquilite y extrayendo la tinta de sus hojas, con lo cual pueden comercializar el colorante en polvo ya que tiene un valor de venta elevado comparado con otros cultivos tradicionales. Así también, las plantas de Xiquilite se pueden cultivar en asocio con maíz y otras plantas de alimentos principales, beneficiándolas con la introducción de nitrógeno a la tierra.

En el caso del uso del añil para el teñido de fibras textiles naturales, especialmente el algodón y el lino, su uso se ha intensificado debido al azul intenso que produce y al deseo creciente de los consumidores de vestir productos teñidos con colorantes naturales. Sin embargo, no es suficiente que sea atractiva la estética de los colorantes naturales en general. También deben de satisfacer los rigores y criterios que se han llegado a establecer para los colorantes sintéticos usados en textiles, especialmente en términos del impacto en la salud de las personas que los trabajan, de los consumidores que los usan en su vestuario y en el medio ambiente.

Por lo tanto, es importante que los artesanos y las pequeñas empresas hogareñas que usan el añil como colorante natural, lo hagan con métodos que sean eficientes, ecológicos y repetibles, los cuales no deben ser dañinos a la salud personal ni impactar negativamente al medio ambiente con desechos químicos altamente contaminantes.

El añil es un colorante de tipo tina, que no requiere mordiente ${ }^{4}$, pero que requiere de un proceso especializado de teñido denominado oxido-reducción; el baño del tinte debe ser alcalino y el agua reducida de oxígeno, ya que solo bajo estas dos condiciones el polvo de añil se disolverá en el baño para poder ser aplicado a una fibra textil natural. El método más utilizado en El Salvador para reducir el oxígeno del baño es usando productos químicos que reducen el tiempo de preparación del baño, siendo los más comúnmente usados el hidrosulfito de sodio como reductor y la soda caustica (hidróxido de sodio) para generar el medio alcalino. Estos dos químicos son tóxicos y corrosivos, provocando impactos negativos a mediano y largo plazo tanto en la salud personal como en el medio ambiente.

Uno de los propósitos principales de la investigación acá reportada fue ofrecer a los teñidores y teñidoras una manera natural, orgánica para teñir usando el añil. Este método de teñido orgánico permitirá a los artesanos y artesanas beneficios sostenibles tanto de salud como económicos, así como una disminución en el impacto negativo al medio ambiente. 


\section{Antecedentes Históricos del Teñido Orgánico}

El añil es considerado el colorante más antiguo y el único colorante azul usado por muchas culturas en lugares distantes a través de todos los continentes. Fue encontrado en telas teñidas cubriendo momias de hace 5,000 años y en las prendas de Tutankamón (Vuorema, 2008); antiguos egipcios, griegos y romanos utilizaban el añil como maquillaje, en crayones y pinturas, así como para teñir telas; el añil ha sido también mencionado en las historias de Herodoto (circa 450 B.C.) (Balfour-Paul, 2000).

India es considerada el centro más antiguo en la producción y teñido del añil en el Viejo Mundo. Fue el principal suministrador de añil en Europa ya en la época GrecoRomana. La asociación de la India con el añil se ve reflejada en la palabra griega del

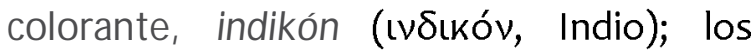
romanos latinizaron el término a indicum, el cual pasó al dialecto italiano y eventualmente al inglés como la palabra índigo (Krieger\&Connah, 2006).La independencia en la India (1947) se luchó y se ganó en parte por la comercialización del añil (Wipplinger, 1996).

Los cruzados consideraron al añil como un tipo de "especie" y lo llevaron a Europa desde Asia Central entre los Siglos XI y XIII (Balfour-Paul, 2000). Por siglos, los teñidores europeos habían usado la planta woad (Isatis tinctoria) para lograr tonos azules, por lo que los agricultores de woad lucharon contra la introducción del añil, que era más barato y producía un azul más intenso. Así, el añil fue prohibido en Francia y en partes de Alemania en 1598: Ios teñidores tenían que jurar, bajo pena de muerte, que ellos no utilizarían el añil para teñir (Gilbert \& Cooke, 2001). En el Siglo $X V I I$, el añil era el producto de comercio más importante de las compañías holandesas y británicas de las Indias Orientales (Balfour-Paul, 2000).

Cuando el añil estuvo ampliamente disponible en Europa en el siglo XVI, teñidores europeos tuvieron muchos problemas para usar el añil debido a su naturaleza insoluble en agua. También, se requerían varias manipulaciones químicas, algunas con materiales tóxicos que provocaban daños en la salud de los trabajadores. Un proceso para la producción de añil en Europa en la era preindustrial era disolver el añil en orina fermentada (Ferreira, Hulme, McNab \& Quye, 2004). Denis-Bernard Quatremère d'lisjonval, ganador de un concurso patrocinado por la Academia de Ciencias de Paris en 1777, recomendaba el uso del polvo de la raíz de madder (Rubia tinctorum) y afrecho de trigo como agentes de fermentación (reductores) para evitar la sobre- o baja-fermentación obtenida con orina fermentada (Lowengard, 2007).

Por otro lado, la evidencia más antigua de teñido con añil en J apón data del siglo X. En japonés, el teñido con añil se denomina aizome, que tiene sus raíces en el período Heian (794-1185); ya en el período Kamakura (1192-1333) el método japonés estaba bien establecido. La cultura japonesa del ai-zome tuvo su mayor desarrollo en el periodo Edo (1600-1868) cuando se aprobaron leyes que impedían que las clases más bajas se vistieran con 
seda y, entonces, el algodón se convirtió en la alternativa popular (Kobo, 2011).

Hay cinco materiales básicos usados en el método japonés de teñido con añil: Sukumo (hojas de la planta de añil japonés), fusuma (afrecho de trigo), sake, ceniza de madera dura y cal. El teñido Ai-zome es un proceso muy largo y complicado; sake y afrecho facilitan el proceso de fermentación, la ceniza de madera (lejía de ceniza o aku) y la cal se utilizan para controlar los niveles de alcalinidad del baño; la cal normalmente se agrega tres veces directamente al baño.

Todos estos materiales se mezclan en una pila grande (500 litros aproximadamente) y moderadamente calentados (entre $20-25^{\circ} \mathrm{C}$ ). El baño es fermentado durante aproximadamente una semana. El baño está enterrado en el suelo para mantener más fácilmente la temperatura estable. El proceso de fermentación determina grandemente la calidad final del tinte producido. En el proceso ideal de fermentación, se forma una espuma como esponja (llamado ai-no-hana o flores de índigo) en la parte superior del baño (Kobo, 2011).

Para la economía y sociedad centroamericana y en especial para El Salvador, el añil tuvo mucha importancia, ya que fue durante más de tres siglos (1500 - 1800) el principal producto de exportación. El añil se volvió parte integrante de la cultura salvadoreña y fue responsable de las principales transformaciones económicas, sociales y políticas del país durante la época (Rivera, Martínez \& Merlos, 2007).
Cada cultura, cada aldea, cada teñidor o teñidora tiene una forma singular de hacer funcionar la magia del añil. Abundan los rituales alrededor del éxito de la extracción y teñido; se desarrollan historias sobre por qué un baño tuvo éxito y otro no. Teñir con añil es el proceso más difícil de efectuar dentro de los colorantes naturales.

Sarah Leonowens (2007), en su tesis de licenciatura, reporta un formulado orgánico utilizado en Guatemala y en Chalchuapa, El Salvador, y descrito por Samako Tamura en su libro "Colorantes Naturales" (Tamura, 1994). El método es reportado como no muy práctico por la dificultad del mantenimiento que se tiene que proporcionar al baño, ya que se tiene que mezclar bien dos veces al día; pero con un buen mantenimiento, el baño puede durar hasta un máximo de tres meses.

Los materiales utilizados son: Polvo de añil: $200 \mathrm{~g}$; afrecho de trigo: $200 \mathrm{~g}$; agua hirviendo: 20 L; cal hidratada: 200 g; glucosa: $200 \mathrm{~g}$. Las instrucciones para la preparación del baño son las siguientes:

1 Se disuelve el afrecho de trigo con agua caliente.

2. Se mezclan todos los materiales sobrantes en un recipiente profundo.

3. Se vierte el agua caliente por pocos.

4. Al siguiente día el baño está listo para teñir: se mezcla bien el líquido azul hasta que toma un color verde amarillo lo que significa que está activado el tinte.

5. Medir la alcalinidad del baño para verificar que tenga un $\mathrm{pH}^{5}$ entre 10.5 y 12. 
Es interesante hacer notar que la autora reporta un periodo de fermentación del baño de solo un día, a diferencia de otros formulados que reportan de una a dos semanas de fermentación.

A. Roquero (1995) reporta en su artículo sobre los colorantes en América prehispana que el colorante añil está presente en variadas formas de expresión artística, telas teñidas, arquitectura, etc. El añil fue muy apreciado por las culturas Aztecas e Incas; entre los antiguos Mayas constituyó un elemento de culto presente en todos sus rituales. Se ha confirmado la presencia del añil en varios tejidos peruanos mediante el análisis cromatográfico, pero no se han encontrado evidencias de su uso en el área de Mesoamérica (Fester, 1955).

Es interesante hacer notar que los primeros cronistas de la época Colonial no mencionan ni al Xiquilite ni al añil entre los muchos colorantes descritos, y es sintomático de la escasa evidencia de su uso entre los indígenas, tanto que los españoles después de haber iniciado la explotación de otros colorantes autóctonos, ellos introdujeron en algunas colonias la planta europea woad, productora de índigotina (Bonavente, 1988).

Pero el hecho de que la planta Xiquilite y el colorante añil posean nombre propio en las principales lenguas de la América prehispana: anganchi, llangua y mutuicube en el área Andina, ch'oh entre los mayas, y xiuhquilitl en la lengua náhuatl de los aztecas, esto remite a un pasado prehispánico (Sahagún, 1985).
Todavía existe en algunas regiones de Latino América teñidores y/o teñidoras que utilizan métodos tradicionales para preparar el baño de teñido con añil, usando productos auxiliares de origen orgánico para provocar la reducción del baño (e.g. orines fermentados o plantas especificas) (Roquero, 1995). Los pasos para preparar el baño, aunque sujetos a variantes locales, son reportados de acuerdo al proceso siguiente:

1 Molido de la piedra de añil.

2. Emulsión del polvo de añil en una solución de lejía, a partir de cenizas vegetales.

3. Vertido de la emulsión en el baño que contiene la tinta.

4. Reducción del baño mediante la adición de sustancias alcalinas (fermentación amoniacal de orines, lejías, aguas de cal sobrante de haber cocido maíz para las tortillas, etc.) o bien mediante un proceso bioquímico de fermentación producido por determinadas plantas locales.

5. Realizar el proceso de reducción a temperatura ambiente, y no sobrepasar $\operatorname{los} 60^{\circ} \mathrm{C}$.

6. Dejar reposar el baño para que los reductores actúen durante la fermentación.

Otro método antiguo reportado en la literatura utiliza arroz o trigo para la fermentación, aunque se reconoce que la preparación del baño de teñido es un poco tardado, pero brinda un azul muy intenso en todas las fibras naturales, si se prepara correctamente (Wipplinger, 1996). Los ingredientes utilizados son: polvo de añil,

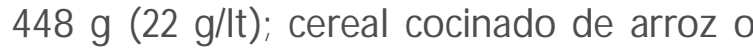
trigo, $224 \mathrm{~g}$ (11 g/tt); polvo de raíces de 
madder o chapi, $224 \mathrm{~g}$ (11 g/tt); carbonato de sodio completamente disuelto en 12 It de agua hirviendo, $1,000 \mathrm{~g}$ (50 g/tt); agua, $20 \mathrm{lt}$.

Se mezclan todos los ingredientes en una olla y se mantiene la mezcla a $30^{\circ} \mathrm{C}$ por entre 7 y 14 días. El baño de añil se debe mezclar bien cada mañana. Cuando la mezcla ha desarrollado un olor desagradable, nata o espuma en la superficie y tenga un color amarillo verdoso, estará lista para usarse. La receta sirve para teñir un aproximado de 4 $\mathrm{kg}$ de fibra a un tono intermedio (Wipplinger, 1996).

En resumen, todos los métodos para la preparación del baño de teñido con añil, reportados en la literatura y que utilizan productos auxiliares naturales, requieren de un proceso de reducción en un medio alcalino; esta se obtiene a través de un proceso de fermentación de algunos ingredientes que donan los radicales necesarios para el secuestro del oxígeno existente en el baño, consiguiendo así la reducción del añil y por consiguiente su solubilidad en el medio acuoso. Los materiales auxiliares para lograr la reducción en un medio alcalino son variados: la cal hidratada, cenizas de madera, agua de lejía, etc. son utilizados para obtener un medio alcalino en el baño ( $\mathrm{pH}$ entre 11 y 12$)$; sake, afrecho de trigo, glucosa, raíz de madder, cereal cocinado de arroz, etc. son utilizados como agentes de fermentación (reductores).

\section{Procesos Químicos durante el teñido del Añil}

La estructura del añil fue primeramente sugerida por von Bayer en 1869 (Clark,
Cooksey, Daniels \& Withnall, 1993). El añil por sí mismo no existe en las hojas del Xiquilite. En lugar, hay precursores como el Indican en las especies Índigofera (Perkin \& Bloxam, 1907), los cuales han sido identificados como indoxil- $\beta$-D-glucosideo. La Figura 1 muestra la formula molecular del Indican.

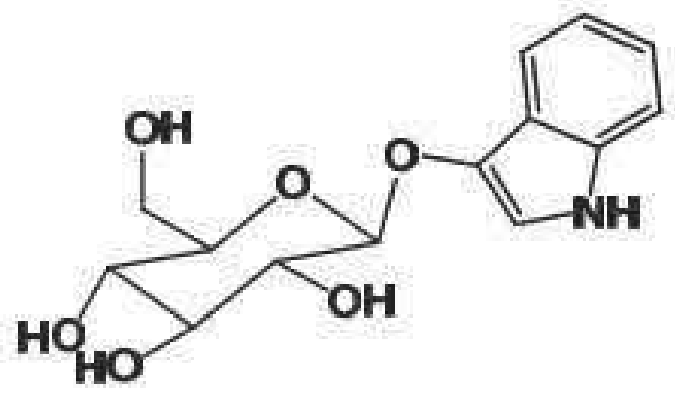

Figura 1 indoxil- $\beta$-D-glucósideo = Indican .

Ha sido sugerido que moléculas libres de Indoxil pueden formar el colorante añil por radicales Indoxil, los cuales primero forman el leuco-índigo y luego es oxidado para formar el añil (Russell \&Kaupp, 1969). El leuco-índigo es la forma reducida del añil, el cual se necesita más tarde durante el proceso de teñido por su solubilidad en agua, mientras que el añil por sí mismo no es soluble en agua $u$ otros solventes usados comúnmente (Clark et al, 1993).

El método de extracción del añil usa la solubilidad en agua de los precursores del añil, remojando las hojas del Xiquilite en agua caliente. Los precursores se rompen en Indoxil y azúcar fraccionada por las enzimas de la planta, aunque en extracciones industriales esto se hace por medio de álcalis y aeración (Minami, Kanafuji \& M iura, 1996). Ver la Figura 2 para 
un detalle completo del proceso de formación del añil a partir del Indoxil.
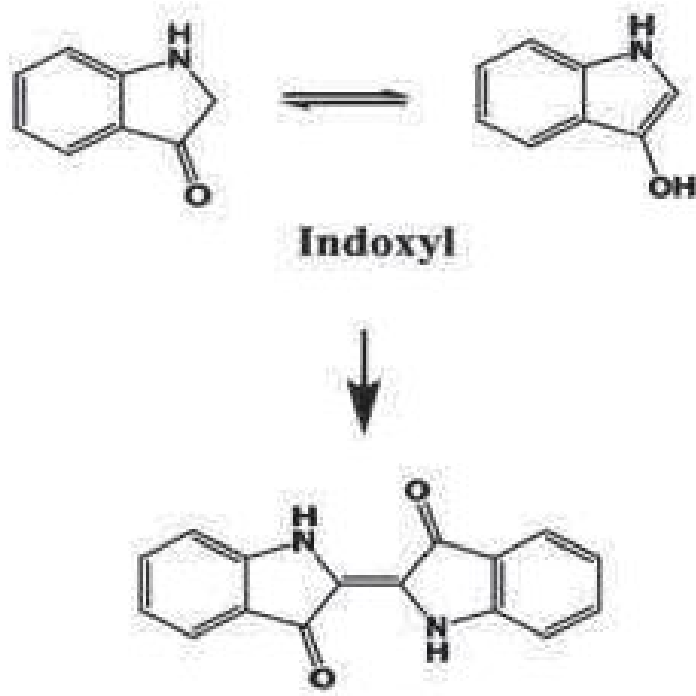

Indigo

Figura 2. Las formulas moleculares de indoxil e índigo.

Como colorante tina, el añil necesita ser reducido a una forma soluble en agua antes de que pueda ser usado en teñido. La reducción del añil a leuco-índigo representa un importante proceso, el cual es efectuado mundialmente en una escala considerable (Roessler \& Crettenand, 2004). Los colorantes tina tienen generalmente un sistema conjugado dicarbonil, el cual es reducido con un cambio en la conjugación.

La reducción es un cambio de dos electrones y el resultado es un alcohol dihídrico que puede ser fácilmente reoxidado (Johnson, 1989). Esta forma reducida se denomina compuesto leuco, que viene de la palabra griego leucos que significa blanco, y se refiere al cambio de color del líquidotina después de la reducción (Božič\&Kokol,2008). En el caso del añil, el color del compuesto leuco es verde amarillo. La Figura 3 muestra el proceso químico de reducción.

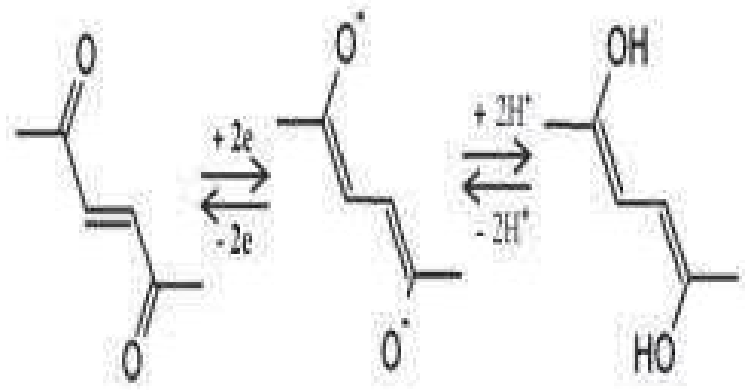

Colorante tina Compuesto levico Acidotina

Figura 3. Proceso de reducción del sistema conjugado dicarbonil de los colorantes tina.

Dependiendo del pH del baño de teñido, el colorante tina puede ser sometido a una ionización de dos pasos desde la forma no iónica hacia las formas mono-iónica o diiónica, siendo la forma no-iónica denominada acido tina (J ohnson, 1989). En el caso del añil, los valores $p K a^{6}$ han sido determinados para pK1 de 8.0 y para pK2 de 12.7 (Etters, 1995). El grado de ionización tiene un efecto sobre la afinidad de índigo por las fibras de algodón que son el sustrato más común para añil debido a la popularidad de la mezclilla.

El añil así como las fibras de celulosa es ionizado negativamente en baños con pH alto. La celulosa contiene grupos $\mathrm{OH}$, los cuales empiezan ser desprotonados ${ }^{7}$ cuando el pH del baño de teñido se incrementa a 11, arriba del cual la desprotonación ocurre más fuertemente. 
La forma no-iónica del añil a valores pH menores tiene baja solubilidad en el baño de teñido así como baja sustantividad hacia las fibras celulósicas. Mientras, la forma diiónica tiene alta solubilidad pero baja sustantividad. La forma mono-iónica ha sido identificada como la más eficiente forma de añil y predomina en el rango de pH entre 10.8 y 112 (Etters, 1995). Así, la absorción de equilibrio del añil en algodón está en su punto más alto en un baño con un $\mathrm{pH}$ aproximado de 11 (Etters, 1991).

Varios métodos han sido desarrollados para la reducción y teñido del añil, todos los cuales comienzan desde el baño de fermentación, el cual ha sido usado por mucho tiempo desde antes que la tecnología moderna apareciera.

El añil puede ser usado en teñido con un baño de fermentación, en donde se convierte en leuco-índigo por medio de una bacteria reductora (Padden, Dillon, John, Edomnds, Collins \& Alvarez, 1998). Se ha sugerido que la bacteria presente en el baño es la Desmobacterium hydrogeniferum, la cual puede estar involucrada en el proceso de reducción (Hurry, 1930).

También ha sido sugerido (Hurry, 1930) que las sustancias orgánicas al baño son fermentadas y convertidas en glucosa, la cual actúa como un agente reductor en el licor alcalino y convierte el añil en leucoíndigo, al mismo tiempo que el azúcar es oxidado y convertido a ácido láctico y luego a acido butírico.

La glucosa ha sido conocida por algún tiempo como un agente reductor para colorantes sulfurosos, pero su uso con colorantes tina es considerado insatisfactorio por su dependencia a altas temperaturas. Esto puede superarse teniendo condiciones altamente alcalinas en el baño de teñido (Chavan, 2001). Recientemente, la glucosa y otros azucares reductores han sido estudiados como posibles agentes reductores, amigables al medio ambiente para usar con colorantes sulfurosos, pero los detalles no son dados en la publicación (Blackburn \& Harvey, 2004).

La glucosa es sometida a una secuencia de degradación compleja en soluciones alcalinas (Ferrier \& Collins, 1972), y ha sido sugerido que el efecto reductor de la glucosa está vinculado a una degradación intermedia en la misma glucosa (Ghanem, Compton, Coles, Canals, Vuorema, John \& Marken, 2005), y en donde, en el proceso de degradación, intermediarios deshidratados con sistemas $\pi$ son seguramente agentes reductores activos REDOX. El proceso de degradación de la glucosa depende de la concentración del álcali (Bamford \& Collins, 1950), así la concentración de intermediarios específicos depende en la concentración del álcali. Esto explica por qué alta alcalinidad es considerada necesaria para los procesos de reducción.

\section{Desarrollo del Trabajo de Investigación}

\section{Trabajo Preliminar}

El trabajo de investigación para la determinación de una fórmula que se pudiese considerar $100 \%$ orgánica, se desarrolló en una casa facilitada por la 
alcaldía del pueblo de Comasagua, Departamento de La Libertad. Los primeros pasos, después de establecer los objetivos y el plan de la investigación, fueron determinar las concentraciones ideales de los productos auxiliares a utilizar con el fin de obtener un medio alcalino con un $\mathrm{pH}$ entre 11 y 12 , y la optimización del proceso de fermentación para una maximización del proceso de reducción del añil.

Se seleccionaron los productos auxiliares a utilizarse para la preparación del baño de fermentación ${ }^{8}$ (reducción), a saber: afrecho de trigo y melaza como agentes reductores y cal hidratada como agente de control de la alcalinidad.

El primer paso fue determinar el valor $\mathrm{pH}$ de cada producto auxiliar; se disolvieron cinco gramos de cada uno en $200 \mathrm{ml}$ de agua potable $(\mathrm{pH}=8.1) \mathrm{a}$ temperatura ambiente, obteniendo los siguientes resultados:

\begin{tabular}{l|l}
\hline Producto & Valor de $\mathrm{pH}$ \\
\hline Cal hidratada & 117 \\
\hline Afrecho & 6.45 \\
\hline Melaza & 5.61 \\
\hline
\end{tabular}

La mezcla de $50 \mathrm{ml}$ de cada solución dio un $\mathrm{pH}$ final de 115 a $25^{\circ} \mathrm{C}$ y fue denominada mezcla \#001 Para determinar el efecto de la concentración de cada producto auxiliar, se hicieron otras tres mezclas en $200 \mathrm{ml}$ de agua, a saber:

\begin{tabular}{clccc}
\hline $\begin{array}{c}\text { Mezcla } \\
\#\end{array}$ & Producto & $\begin{array}{c}\text { Concentración } \\
(\mathrm{g})\end{array}$ & \multicolumn{2}{c}{$\begin{array}{c}\text { Valor de Temperatura } \\
\mathrm{pH}\end{array}$} \\
\hline 002 & afrecho & 5.0 & 11.45 & 23.0 \\
& cal & 2.0 & & \\
& melaza & 5.0 & & \\
\hline 003 & afrecho & 5.0 & 11.46 & 22.8 \\
& cal & 5.0 & & \\
& melaza & 8.0 & & \\
\hline 004 & afrecho & 5.0 & 11.50 & 23.1 \\
& cal & 5.0 & & \\
& melaza & 10.0 & &
\end{tabular}

Después de una hora en reposo, el pH de cada solución fue medido y se obtuvieron los siguientes resultados:

\begin{tabular}{l|l|l}
\hline Mezcla \# & Valor de $\mathrm{pH}$ & $\begin{array}{l}\text { Temperatura } \\
\left({ }^{\circ} \mathrm{C}\right)\end{array}$ \\
\hline 001 & 10.87 & 23.3 \\
\hline 002 & 1147 & 23.4 \\
\hline 003 & 1151 & 23.4 \\
\hline 004 & 1152 & 23.6 \\
\hline
\end{tabular}

Después de tres días, el pH fue nuevamente medido y los resultados fueron:

\begin{tabular}{|c|c|c|}
\hline $\begin{array}{c}\text { Mezcla } \\
\#\end{array}$ & Valor de Ph & $\begin{array}{c}\text { Temperatura } \\
\left({ }^{\circ} \mathrm{C}\right)\end{array}$ \\
\hline 001 & 10.72 & 22.2 \\
\hline 002 & 1149 & 22.0 \\
\hline 003 & 1150 & 22.2 \\
\hline 004 & 1145 & 22.3 \\
\hline
\end{tabular}
concentraciones de los productos auxiliares no tenían mayor efecto en el pH final de la solución y que el pH se mantenía estable después de varios días de preparado, con excepción de la solución \#001 que mostró 
una disminución en el pH. Se procedió entonces a optimizar la fórmula de la solución fermentadora.

\section{Desarrollo de Solución Fermentadora}

Para optimizar la cantidad de productos auxiliares a utilizar en el formulado orgánico, se prepararon otras soluciones con diferentes concentraciones en $200 \mathrm{ml}$ de agua, y estos fueron los resultados:

\begin{tabular}{|c|c|c|c|c|}
\hline Mezcla \# & Producto & $\begin{array}{l}\text { Concentración } \\
\text { (g) }\end{array}$ & $\begin{array}{c}\text { Valor de } \\
\text { pH }\end{array}$ & $\begin{array}{c}\text { Temperatura } \\
\left({ }^{\circ} \mathrm{C}\right)\end{array}$ \\
\hline 005 & $\begin{array}{l}\text { afrecho } \\
\text { cal } \\
\text { melaza }\end{array}$ & $\begin{array}{l}3.0 \\
2.0 \\
6.0\end{array}$ & 1132 & 23.3 \\
\hline 006 & $\begin{array}{l}\text { afrecho } \\
\text { cal } \\
\text { melaza }\end{array}$ & $\begin{array}{l}5.0 \\
4.0 \\
5.0\end{array}$ & 1171 & 23.9 \\
\hline 007 & $\begin{array}{l}\text { afrecho } \\
\text { cal } \\
\text { melaza }\end{array}$ & $\begin{array}{l}5.0 \\
5.0 \\
5.0\end{array}$ & 12.11 & 24.0 \\
\hline 008 & $\begin{array}{l}\text { afrecho } \\
\text { cal } \\
\text { melaza }\end{array}$ & $\begin{array}{l}5.0 \\
4.0 \\
6.0\end{array}$ & 12.06 & 24.0 \\
\hline 009 & $\begin{array}{l}\text { afrecho } \\
\text { cal } \\
\text { melaza }\end{array}$ & $\begin{array}{l}5.0 \\
3.0 \\
5.0\end{array}$ & 1196 & 24.0 \\
\hline 010 & $\begin{array}{l}\text { afrecho } \\
\text { cal } \\
\text { melaza }\end{array}$ & $\begin{array}{l}5.0 \\
3.0 \\
3.0\end{array}$ & 1192 & 24.0 \\
\hline 011 & $\begin{array}{l}\text { afrecho } \\
\text { cal } \\
\text { melaza }\end{array}$ & $\begin{array}{l}7.0 \\
4.0 \\
5.0\end{array}$ & 12.0 & 23.9 \\
\hline
\end{tabular}

Después de una hora en reposo, las soluciones \#005 a 011 dieron los siguientes valores de $\mathrm{pH}$ :

\begin{tabular}{l|l|l}
\hline $\begin{array}{c}\text { Mezcla } \\
\#\end{array}$ & \multicolumn{1}{|c|}{$\begin{array}{c}\text { Valor de } \\
\mathrm{pH}\end{array}$} & \multicolumn{1}{|c}{$\begin{array}{c}\text { Temperatura } \\
\left({ }^{\circ} \mathrm{C}\right)\end{array}$} \\
\hline 005 & 1175 & 23.9 \\
\hline 006 & 12.18 & 23.9 \\
\hline 007 & 12.14 & 24.0 \\
\hline 008 & 12.16 & 24.2 \\
\hline 009 & 1198 & 24.1 \\
\hline 010 & 12.05 & 24.0 \\
\hline 011 & 12.16 & 24.0 \\
\hline
\end{tabular}

Estos valores muestran un pequeño incremento, estadísticamente no significativo, de menos de 1\%en la mayoría de los casos, con excepción de la mezcla \#010 que mostró un incremento en $\mathrm{pH}$ de 11\% Se determinó que la concentración de cal hidratada tiene mayor impacto en el valor final del pH de la solución, pero que los valores de $\mathrm{pH}$ de las diferentes soluciones se mantienen después de un corto tiempo.

Basados en los resultados previamente obtenidos y tratando de determinar cual podría ser la solución óptima de los productos auxiliares para un formulado de teñido orgánico, se prepararon nuevas mezclas con la particularidad que cada producto auxiliar fue disuelto por separado en $200 \mathrm{ml}$ de agua, el pH de cada solución fue medido y finalmente se mezclaron los tres productos en un mismo recipiente. 


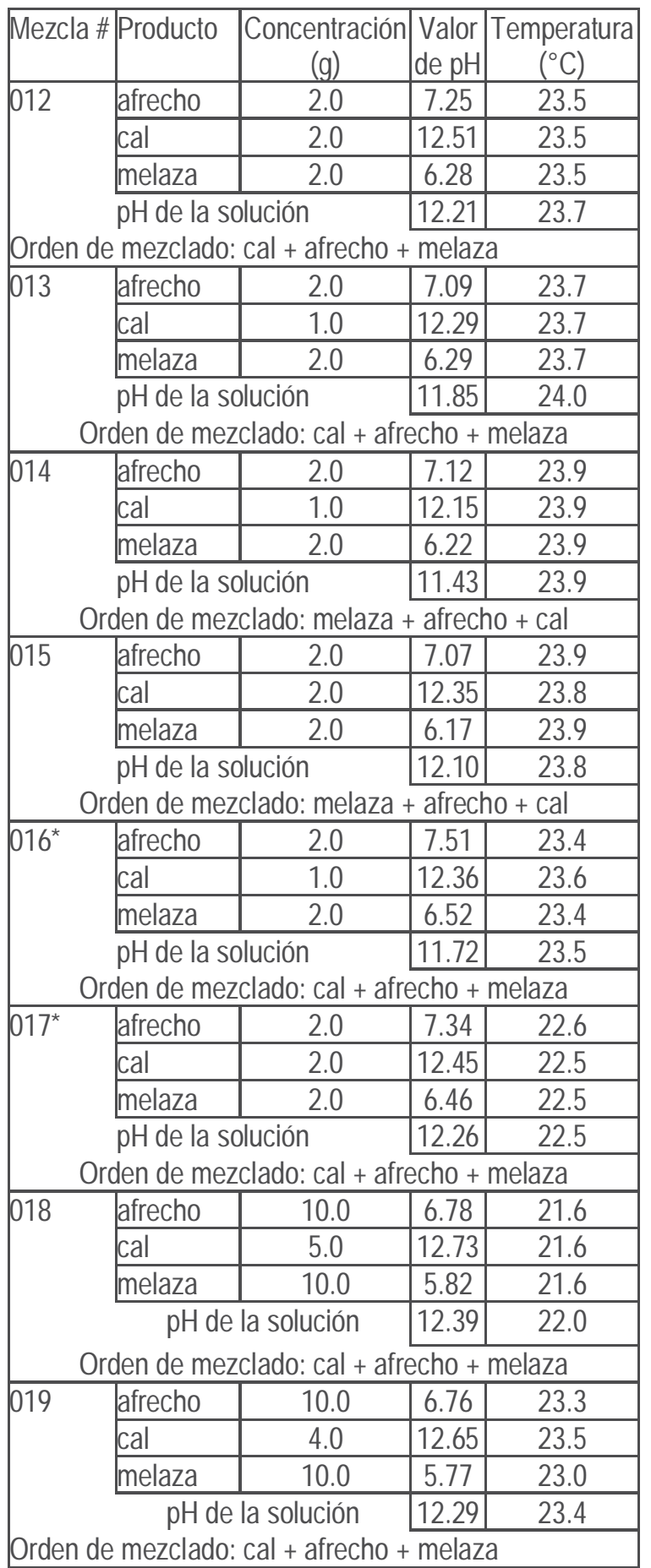

(*) Solución final de $600 \mathrm{ml}$.

El control de pH de cada una de las concentraciones del \#012 al 019 mostró pocas variaciones después de varios días, por lo que se procedió a teñir muestras de tela 100\% algodón (ver sección siguiente de teñido orgánico). Los resultados del teñido no fueron satisfactorios, lo que obligó a reformular las concentraciones y prepararlas en baños de $2 \mathrm{~L}$ de agua, a saber:

\begin{tabular}{|c|c|c|c|c|}
\hline Mezcla \# & Producto & $\begin{array}{c}\text { Concentración } \\
(\mathrm{g})\end{array}$ & \begin{tabular}{|l|} 
Valor \\
de $\mathrm{pH}$
\end{tabular} & $\begin{array}{c}\text { Temperatura } \\
\left({ }^{\circ} \mathrm{C}\right)\end{array}$ \\
\hline \multirow[t]{4}{*}{020} & afrecho & 20.0 & 11.91 & 30.5 \\
\hline & cal & 20.0 & & \\
\hline & melaza & 20.0 & & \\
\hline & pH de la & olución & & \\
\hline \multicolumn{5}{|c|}{ Orden de mezclado: cal + afrecho + melaza } \\
\hline \multirow[t]{4}{*}{021} & afrecho & 20.0 & 12.33 & 33.0 \\
\hline & cal & 18.0 & & \\
\hline & melaza & 18.0 & & \\
\hline & pH de la & olución & 11.85 & 24.0 \\
\hline \multicolumn{5}{|c|}{ Orden de mezclado: cal + afrecho + melaza } \\
\hline
\end{tabular}

(*) Los valores del pH de las dos solucione se mantuvieron relativamente estables después de una hora.

Por razones fortuitas, se observó que el orden de mezcla de los productos auxiliares puede tener un efecto significativo en el pH final de la solución, por lo que se procedió a experimentar con varias soluciones y ordenes de mezcla. La solución \#013 fue repetida y preparada con diferentes órdenes de mezcla, y los resultados obtenidos fueron:

\begin{tabular}{l|c}
\hline Orden de Mezcla & Valor de pH \\
\hline Cal +afrecho +melaza & 12.03 \\
\hline Cal +melaza + afrecho & 1190 \\
\hline Melaza +afrecho +cal & 1148 \\
\hline
\end{tabular}


1 Los baños deben taparse con materiales porosos para que las soluciones respiren para permitir una buena fermentación.

2. Es importante que las soluciones se preparen en baños de por lo menos 20 litros para permitir una buena fermentación también.

Siguiendo los consejos dados, se intentó nuevamente obtener una solución mezclando levadura con afrecho y cal hidratada en un baño de 25 litros. A la vez, se preparó una solución de cal hidratada, afrecho y melaza en un baño de $25 \mathrm{~L}$. Estas dos soluciones fueron replicas a mayor escala de las soluciones \#025 y 021, respectivamente.

\begin{tabular}{|c|c|c|c|c|}
\hline Mezcla \# & Producto & $\begin{array}{c}\text { Concentración } \\
\text { (g) }\end{array}$ & \begin{tabular}{|l|} 
Valor \\
de pH
\end{tabular} & $\begin{array}{c}\text { Temperatura } \\
\left({ }^{\circ} \mathrm{C}\right)\end{array}$ \\
\hline \multirow[t]{4}{*}{024} & afrecho & 3.0 & & \\
\hline & cal & 3.0 & & \\
\hline & levadura & 5.0 & & \\
\hline & pH de la & olución & 12.14 & 23.5 \\
\hline \multicolumn{5}{|c|}{ Orden de mezclado: cal + afrecho + levadura } \\
\hline \multirow{4}{*}{025} & afrecho & 10.0 & & \\
\hline & $\begin{array}{l}\text { agua de } \\
\text { lejía }\end{array}$ & 8.0 & & \\
\hline & levadura & 8.0 & & \\
\hline & $\mathrm{pH}$ de la & olución & 12.31 & 24.9 \\
\hline
\end{tabular}

(*) El afrecho fue disuelto en agua hiviendo; la cal hidratada fue disuelta en agua al tiempo; la melaza y la levadura fueron disueltas en agua tibia.

\section{Teñido Orgánico con Añil}

Las soluciones fermentadoras del \#001 al \#004 en $200 \mathrm{ml}$ de baño fueron utilizadas para el teñido inicial con añil con las siguientes concentraciones de colorante:

\begin{tabular}{c|c|c|c}
\hline $\begin{array}{c}\text { Mezcla } \\
\#\end{array}$ & $\begin{array}{c}\text { Concentración } \\
\text { Añil }(g)\end{array}$ & $\begin{array}{c}\text { Valor } \\
\text { de } \\
\mathrm{pH}\end{array}$ & $\begin{array}{c}\text { Temperatura } \\
\left({ }^{\circ} \mathrm{C}\right)\end{array}$ \\
\hline 001 & 2.0 & 11.10 & 24.0 \\
\hline 002 & 2.0 & 11.42 & 22.7 \\
\hline 003 & 3.0 & 11.50 & 23.6 \\
\hline 004 & 3.0 & 11.50 & 23.5
\end{tabular}

Después de cinco días en reposo, las cuatro soluciones tenían los siguientes valores de $\mathrm{pH}$ :

\begin{tabular}{c|c|c}
\hline Mezcla \# & Valor de pH & $\begin{array}{c}\text { Temperatura } \\
\left({ }^{\circ} \mathrm{C}\right)\end{array}$ \\
\hline 001 & 10.72 & 22.2 \\
\hline 002 & 11.49 & 22.0 \\
\hline 003 & 11.50 & 22.2 \\
\hline 004 & 11.45 & 22.3 \\
\hline
\end{tabular}

Se procedió a teñir muestras de tela de algodón de $10 \times 10 \mathrm{~cm}^{2}$ con las cuatro soluciones con cuatro y seis inmersiones ${ }^{9}$.

Después de cinco días en reposo, las cuatro soluciones tenían los siguientes valores de $\mathrm{pH}$ :

\begin{tabular}{l|l|l|l}
\hline Mezcla \# & $\begin{array}{c}\text { Valorde } \\
\mathrm{pH}^{*}\end{array}$ & $\begin{array}{c}\text { Valor de } \\
\mathrm{pH}^{* *}\end{array}$ & $\begin{array}{c}\text { Temperatura } \\
\left({ }^{\circ} \mathrm{C}\right)\end{array}$ \\
\hline 001 & 10.69 & 10.61 & 23.5 \\
\hline 002 & 11.38 & 11.40 & 23.8 \\
\hline 003 & 11.45 & 11.41 & 23.0 \\
\hline 004 & 11.51 & N/A & 23.8 \\
\hline
\end{tabular}

*Después de 4 inmersiones

** Después de 6 inmersiones

En este caso no se desarrolló el color azul típico del añil en las muestras de tela de algodón, aunque fue notable que todas las 
muestras mostraran buena solidez de color al frotado tanto en seco como en húmedo ${ }^{10}$.

Se concluyó que el tono azul añil no se había desarrollado porque las soluciones solo tenían cinco días de fermentación; pero que si había habido penetración y fijación del poco colorante desarrollado, como las pruebas de frotado lo confirmaron. Esto fue posible porque el $\mathrm{pH}$ de las soluciones se mantuvo entre 11 y 12 durante el teñido, condición necesaria para

\begin{tabular}{l|c|c|c}
\hline Mezcla \# & $\begin{array}{c}\text { Concentración Añil } \\
(\mathrm{g} / \mathrm{L})\end{array}$ & $\begin{array}{c}\text { Valor de } \\
\mathrm{pH}\end{array}$ & $\begin{array}{c}\text { Temperatura } \\
\left({ }^{\circ} \mathrm{C}\right)\end{array}$ \\
\hline $014 \mathrm{~B}$ & 5.0 & 11.1 & 24.0 \\
\hline $014 \mathrm{C}$ & 10.0 & 11.1 & 23.4 \\
\hline $016 \mathrm{~B}$ & 5.0 & 11.7 & 23.3 \\
\hline $016 \mathrm{C}$ & 10.0 & 11.7 & 23.1 \\
\hline
\end{tabular}

que el añil penetre en la fibra de algodón y se fije (Etters, 1995).

El nuevo lote de teñido fue preparado con las soluciones 014 y 016 porque fueron las que mostraron valores de $\mathrm{pH}$ más cercano a 115, el cual fue el valor objetivo a obtener. Las dos soluciones fueron preparadas con dos tipos de concentración de añil: 5 y $10 \mathrm{~g} / \mathrm{L}$.

Después de siete días en reposo, las cuatro soluciones tenían los siguientes valores de $\mathrm{pH}$ :

Se procedió a teñir muestras de tela de

\begin{tabular}{c|c|c}
\hline Mezcla \# & Valor de $\mathrm{pH}$ & $\begin{array}{c}\text { Temperatura } \\
\left({ }^{\circ} \mathrm{C}\right)\end{array}$ \\
\hline $014 \mathrm{~B}$ & 11.9 & 22.7 \\
\hline $014 \mathrm{C}$ & 11.7 & 22.9 \\
\hline $016 \mathrm{~B}$ & 11.5 & 22.0 \\
\hline $016 \mathrm{C}$ & 12.0 & 22.5 \\
\hline
\end{tabular}

algodón con las cuatro soluciones con diez inmersiones. Los valores del $\mathrm{pH}$ de las soluciones después del teñido fueron:

En este caso tampoco se desarrolló el tono

\begin{tabular}{l|l|l}
\hline Mezcla \# & Valor de pH & Temperatura $\left({ }^{\circ} \mathrm{C}\right)$ \\
\hline $014 \mathrm{~B}$ & 11.9 & 23.5 \\
\hline $014 \mathrm{C}$ & 11.7 & 23.8 \\
\hline $016 \mathrm{~B}$ & 11.2 & 23.0 \\
\hline $016 \mathrm{C}$ & 12.0 & 23.8 \\
\hline
\end{tabular}

azul típico del añil en las muestras de tela de algodón con estas nuevas soluciones pese a que se había incrementado significativamente la cantidad de colorante; se especuló nuevamente la falta de fermentación para la completa disolución del añil.

En esta oportunidad, las soluciones \#014B y 014C no mostraron buena solidez de color al frotado. Es interesante hacer notar que el pH inicial de estas soluciones fue debajo de 115 después de agregar el colorante, lo que podría ser la razón por la cual no hubo buena solidez al frotado y al enjuague. Con las soluciones \#016B y 016C se tiñó con dos métodos: la muestra se mantuvo en constante agitación durante cada inmersión y en reposo durante cada inmersión. La muestra teñida en reposo mostró mayor penetración del colorante, aunque las dos muestras mostraron buena solidez al frotado en seco y en húmedo. Es de puntualizar que el $\mathrm{pH}$ inicial de las dos muestras fue de $\mathbf{1 1 7}$ después que el añil había sido agregado a la solución.

En virtud de los resultados obtenidos con los primeros dos lotes, se decidió teñir en 
baños de dos litros, utilizando las soluciones \#020 y 021 A estas dos soluciones le fueron agregadas añil en una concentración de $10 \mathrm{~g} / \mathrm{L}$. En esta oportunidad, el colorante fue preparado en agua tibia $\left(\approx 30^{\circ} \mathrm{C}\right)$ previo a su incorporación a la solución de fermentación, siendo vertida lentamente a través de las paredes del recipiente del baño para evitar la formación de burbujas de aire. El valor del pH antes del teñido de las muestras fue como sigue:

\begin{tabular}{|c|c|c|}
\hline Mezcla \# & $\begin{array}{l}\text { Valor de } \\
\mathrm{pH}\end{array}$ & $\begin{array}{l}\text { Temperatura } \\
\left({ }^{\circ} \mathrm{C}\right)\end{array}$ \\
\hline $020 \mathrm{E}$ & 119 & 22.7 \\
\hline 021E & 12.1 & 22.9 \\
\hline
\end{tabular}

Muestras de tela de algodón 100\% fueron teñidas con la solución 020E con cuatro, seis y ocho inmersiones; seis y diez inmersiones fueron hechas usando la solución 021E. El valor del pH de cada solución después del teñido fue medido con los resultados siguientes:

\begin{tabular}{|c|c|c|}
\hline Mezcla \# & Valor de pH & $\begin{array}{l}\text { Temperatura } \\
\left({ }^{\circ} \mathrm{C}\right)\end{array}$ \\
\hline $\begin{array}{l}020 \mathrm{E} \\
4 \text { inmersiones }\end{array}$ & 11.90 & 22.0 \\
\hline $\begin{array}{l}020 \mathrm{E} \\
6 \text { inmersiones }\end{array}$ & 11.96 & 22.0 \\
\hline $\begin{array}{l}020 \mathrm{E} \\
8 \text { inmersiones }\end{array}$ & 11.84 & 22.2 \\
\hline $\begin{array}{l}021 \mathrm{E} \\
10 \mathrm{inmersiones}\end{array}$ & 11.83 & 25.0 \\
\hline
\end{tabular}

En las telas teñidas con la solución \#020E después de cuatro, seis y ocho inmersiones antes y después del enjuague ${ }^{11}$, puede observarse un mayor desarrollo del color azul añil al teñirse en un baño de dos litros, aunque no lo suficiente para considerar el color satisfactorio. Además, las muestras teñidas no mostraron buena solidez al frotado en seco y húmedo.

Con las telas teñidas con la solución \#021E después de diez y seis inmersiones, nuevamente, no hubo desarrollo del color azul añil debido posiblemente a que la solución había estado en reposo por seis semanas.

A continuación y considerando los resultados obtenidos hasta el momento de la investigación, las soluciones \#026 y 027 con levadura y melaza, respectivamente, fueron utilizadas para teñir muestras de tela de algodón 100\%en baños de 25 litros. A la solución \#026 se le agregaron $4 \mathrm{~g} / \mathrm{L}$ de añil y a la \#027 se le agregaron $10 \mathrm{~g} / \mathrm{L}$. Los valores $\mathrm{pH}$ de las soluciones fueron:

\begin{tabular}{l|l|l}
\hline Mezcla \# & $\begin{array}{l}\text { Valor de } \\
\mathrm{pH}\end{array}$ & $\begin{array}{l}\text { Temperatura } \\
\left({ }^{\circ} \mathrm{C}\right)\end{array}$ \\
\hline 026B & 12.2 & 23.7 \\
\hline 027E & 12.2 & 25.1 \\
\hline
\end{tabular}

Las soluciones \#026 y 027se mantuvieron en reposo por dos y tres semanas, respectivamente. El pH de cada solución después del tiempo de reposo fue de:

\begin{tabular}{l|l|l}
\hline Mezcla \# & $\begin{array}{l}\text { Valor de } \\
\mathrm{pH}\end{array}$ & $\begin{array}{l}\text { Temperatura } \\
\left({ }^{\circ} \mathrm{C}\right)\end{array}$ \\
\hline 026B & 11.5 & 22.8 \\
\hline 027E & 12.0 & 22.8 \\
\hline
\end{tabular}


Las muestras de tela fueron teñidas con seis inmersiones usando la solución \#026B, y con cuatro, seis y ocho inmersiones utilizando la solución \#027E. El valor del pH de cada solución después del teñido fue medido con los resultados siguientes:

\begin{tabular}{c|c|c}
\hline Mezcla \# & $\begin{array}{c}\text { Valor de } \\
\mathrm{pH}\end{array}$ & Temperatura $\left({ }^{\circ} \mathrm{C}\right)$ \\
\hline 026B & 11.86 & 24.1 \\
\hline 027E & 12.31 & 23.1 \\
\hline
\end{tabular}

Después de seis inmersiones de las muestras de tela en la solución \#026B no se notó ni penetración ni fijación del colorante en la tela, por lo que se procedió a descartar esta solución. Se concluyó que el colorante no se había disuelto adecuadamente en la solución debido a falta de fermentación; se especuló que el tipo de levadura ${ }^{12}$ utilizada había causado la falta de fermentación adecuada.

En las telas teñidas con la solución \#027E después de cuatro, seis y ocho inmersiones, puede observarse en general, que las telas muestran el color azul característico del añil a diferentes intensidades dependiendo del número de inmersiones aplicadas.

Es interesante hacer notar que la fijación del colorante a la tela fue más alta después del enjuague. Las pruebas de solidez al frotado mostraron poca transferencia después del secado total de las muestras y del enjuague.

En la tela teñida en ocho inmersiones con la solución \#027E, con secado parcial ${ }^{13} y$ después del enjuague, puede observarse, el tono del azul es bastante intenso y similar al azul añil de mediano tono; también se puede observar que la fijación del colorante fue bastante buena como lo muestran las tiras de tela de las pruebas de solidez al frotado.

En la tela teñida con ocho inmersiones con la solución \#027E, con secado total ${ }^{11}$, nuevamente se observó que la muestra sin enjuague tiene un tono menor de azul que la muestra después del enjuague. Esto confirma la necesidad de un enjuague adecuado para el desarrollo completo del color y la oxidación del colorante que permite su fijación en la fibra.

Comparando las muestra con secado parcial y secado total, se puede inferir por los colores obtenidos al final que hay mejor desarrollo del tono azul cuando el enjuague se hace con secado parcial.

Para evaluar el sangrado ${ }^{12}$ del colorante durante el enjuague y determinar el arrastre efectivo de colorante ${ }^{13}$, se estableció el siguiente protocolo:

1 Pesar muestra antes del teñido $\left(P_{0}\right)$.

2. Teñir muestra con un número específico de inmersiones.

3. Dejar secar la muestra totalmente después de la última inmersión. 
4. Pesar la muestra teñida y secada (P1) para determinar el arrastre total (AT).

5. Iniciar enjuague con un litro de agua de chorro y a temperatura ambiente, introduciendo la tela cinco veces en el baño de enjuague.

6. Repetir el paso \#5 dos veces más, y etiquetar estos baños de enjuague secuencialmente.

7. Medir los valores del total de sólidos disueltos (TSD) en partes por millón (ppm) en el agua residual del baño de enjuague, y de $\mathrm{pH}$ en cada uno de los tres baños.

8. Terminar de enjuagar con agua corriente hasta que la muestra ya no sangra colorante visiblemente.

9. Secar la muestra completamente.

10. Pesar la muestra secada (P2) para determinar el arrastre efectivo $\left(A_{E}\right)$.

El arrastre y sangrado se determinan utilizando las siguientes formulas:

$$
\begin{gathered}
\text { Arrastre Total }\left(A_{T}\right)=P_{1}-P_{0} \\
\text { Arrastre Efectivo }\left(A_{E}\right)=P_{2}-P_{0}
\end{gathered}
$$$$
\text { Sangrado }(\%)=\left[\left(P_{1}-P_{2}\right) \div P_{1}\right] \times 100
$$

El protocolo fue utilizado en muestras teñidas con ocho inmersiones usando la solución \#027E y con secado parcial. Estos fueron los resultados:
Muestra \#1

\begin{tabular}{l|l|l|l}
\hline $\begin{array}{l}\text { Enjuague } \\
\#\end{array}$ & $\begin{array}{l}\text { Valor } \\
\text { de TDS } \\
\text { (ppm) }\end{array}$ & $\begin{array}{l}\text { Valor } \\
\text { de } \mathrm{pH}\end{array}$ & $\begin{array}{l}\text { Temperatura } \\
\left({ }^{\circ} \mathrm{C}\right)\end{array}$ \\
\hline 1 & 144.3 & 8.92 & 24.2 \\
\hline 2 & 115.2 & 8.61 & 24.3 \\
\hline 3 & 110.0 & 8.52 & 24.8 \\
\hline $\begin{array}{l}\text { Agua de } \\
\text { chorro }\end{array}$ & 101.7 & 7.63 & 25.4 \\
\hline
\end{tabular}

Muestra \#2

\begin{tabular}{l|l|l|l}
\hline $\begin{array}{l}\text { Enjuague } \\
\#\end{array}$ & $\begin{array}{l}\text { Valor } \\
\text { de TDS } \\
\text { (ppm) }\end{array}$ & $\begin{array}{l}\text { Valor } \\
\text { de } \mathrm{pH}\end{array}$ & $\begin{array}{l}\text { Temperatura } \\
\left({ }^{\circ} \mathrm{C}\right)\end{array}$ \\
\hline 1 & 159.7 & 9.27 & 22.9 \\
\hline 2 & 132.1 & 9.02 & 23.8 \\
\hline 3 & 121.7 & 8.80 & 23.6 \\
\hline $\begin{array}{l}\text { Agua de } \\
\text { chorro }\end{array}$ & 104.5 & 7.96 & 23.6 \\
\hline
\end{tabular}

Como puede observarse de los resultados obtenidos, el valor de TSD y $\mathrm{pH}$ de los baños de enjuague disminuyeron en las dos muestras a medida que se aplicaron los tres baños de enjuague, llegando a valores cercanos a los valores iniciales del agua de 
chorro. Así también, los valores de pH disminuyeron en la medida que la cantidad de añil en el agua residual disminuyó. Estos resultados permiten concluir que la pérdida de colorante durante el enjuague es relativamente poca, lo que confirma los resultados obtenidos en las pruebas de solidez al frotado en seco y en húmedo.

Es de hacer notar que las muestras con seis y ocho inmersiones y con secado total no mostraron sangrado significativo de colorante después del primer enjuague. Después de una medición inicial de 109.9 ppm, las otras dos mediciones fueron cercanas al valor de 101 ppm. También se observó que los valores de pH de cada baño de enjuague fueron muy cercanos al valor de $\mathrm{pH}$ del agua de chorro, con valores de $6.78,6.86$ y 6.89 , respectivamente, y una temperatura de $27.3^{\circ} \mathrm{C}$.

Por lo tanto, se puede concluir que el secado total contribuye a una mayor fijación del colorante en la fibra ya que la exposición al oxigeno del aire se hace de una manera gradual, lográndose un mayor entrampamiento de las micro partículas de añil en la superficie de la fibra.

No se pudo determinar los arrastres total y parcial debido a que la escala de la báscula digital utilizada es en gramos, y las cantidades a pesar del arrastre de colorante es en miligramos.

\section{Conclusiones: Propuesta de Formulado Orgánico para Colorante Añil}

En base a los resultados obtenidos tanto en la formulación del baño de fermentación así como en la formulación del baño de teñido, cuyos resultados han sido dados y explicados en la sección anterior, se recomienda el uso de la siguiente formula de teñido orgánico utilizando el colorante añil, así como el método de preparación y de teñido.

\begin{tabular}{l|l|l}
\hline Ingredientes & Concentración & $\begin{array}{l}\text { Cantidad } \\
\text { Total por } \\
\text { Baño }\end{array}$ \\
\hline Agua potable & & 25 litros \\
\hline Afrecho & $10 \mathrm{~g} / \mathrm{L}$ & $250 \mathrm{~g}$ \\
\hline Cal hidratada & $8 \mathrm{~g} / \mathrm{L}$ & $200 \mathrm{~g}$ \\
\hline Melaza & $8 \mathrm{~g} / \mathrm{L}$ & $200 \mathrm{~g}$ \\
\hline Añil14 & $10 \mathrm{~g} / \mathrm{L}$ & $250 \mathrm{~g}$ \\
\hline
\end{tabular}

Veinte litros de agua a temperatura ambiente deben verterse en un recipiente de plástico lo suficientemente grande para que el baño de tinte no se derrame durante el proceso de teñido, y que el teñidor o la teñidora puedan manejar la prenda a teñir de una manera cómoda y eficiente.

El afrecho debe de disolverse en dos litros de agua caliente $\left(70^{\circ} \mathrm{C}\right)$, utilizando una paleta de madera limpia. La cal hidratada debe de disolverse en un litro de agua al tiempo con una paleta de madera hasta que se note una solución blanquecina. La melaza debe de disolverse en un litro de agua tibia $\left(30^{\circ} \mathrm{C}\right)$ hasta que se forme una pasta semi-liquida. Medir el pH de cada uno de los ingredientes después de disueltos con el papel indicador $\mathrm{pH}$; los valores deben de estar dentro de los rangos dados abajo. 


\begin{tabular}{l|c}
\hline Producto & Valor de $\mathrm{pH}$ \\
\hline Cal hidratada & $11-12$ \\
\hline Afrecho & $6-7$ \\
\hline Melaza & $5-6$ \\
\hline
\end{tabular}

La mezcla de los agentes de fermentación debe hacerse, necesariamente, en el orden siguiente: cal hidratada + afrecho + melaza, vertiendo lentamente uno a uno los materiales, y mezclándolos bien antes de agregar el siguiente.

Después de que los tres materiales han sido mezclados, se debe medir el pH con el papel indicador $\mathrm{pH}$; este debe marcar un valor alrededor de 12 . Si el valor del $\mathrm{pH}$ es muy alto (e.g. 13), agregar el jugo de medio limón indio o hasta que el $\mathrm{pH}$ llegue al rango entre 11 y 12 . Si el valor del pH está demasiado bajo (acido), añadir cal hidratada en tantos de $10 \mathrm{~g}$, hasta que el baño alcance el pH correcto.

El añil debe de disolverse en un litro de solución previamente fermentada (si se tiene) a una temperatura de 30 a $35^{\circ} \mathrm{C}$.

Luego, debe de verterse poco a poco en la solución de fermentación ya preparada, cuidando de hacerlo por las paredes del recipiente y muy cerca del nivel superior del baño, para evitar la formación de burbujas de aire que pueden impedir la correcta reducción del añil.

Medir el valor del pH del baño de teñido, el cual debe estar en el rango de 11 y 12 . Tapar el recipiente con una manta de algodón $100 \%$ la cual debe ser no muy densa para permitir una circulación apropiada de aire, requerida para la correcta fermentación de la solución (reducción del añil).

El baño de teñido se debe mezclar bien con una paleta de madera cada mañana, y debe mantenerse el baño sin uso entre 25 y $30^{\circ} \mathrm{C}$ por 7 días, aunque de preferencia esperar 14 días antes de utilizar el baño para teñir.

Cuando el baño desarrolle un olor intenso, nata o espuma en la superficie y tenga un color amarillo verdoso, este está listo para usarse.

Los resultados obtenidos utilizando una formula orgánica pueden diferir con respecto al teñido con formulados químicos en relación a la intensidad del azul. Puede decirse que una muestra de algodón $100 \%$ teñida con ocho inmersiones en un formulado químico tendrá un azul más intenso que una teñida con un formulado orgánico.

Los consumidores apreciarán saber que las prendas que ellos visten han sido teñidas mediante procesos que son amigables al medio ambiente y no causan daño en la salud de los trabajadores y trabajadoras. Esta información se puede utilizar para el mercadeo de sus productos teñidos con un formulado orgánico.

Finalmente, hay que recordar que el proceso de extraer el añil y teñir con él es un arte. Es necesario experimentar continuamente y hacer cambios hasta llegar a un sistema efectivo propio. 


\section{Recomendaciones}

Las siguientes recomendaciones se hacen basadas en la experiencia personal y profesional de los investigadores, y en la información técnica encontrada en la literatura.

1 Debe de entenderse que el teñido con el colorante añil utilizando una formula orgánica es diferente en varios aspectos al teñido con una formula química ${ }^{15}$.

2. El uso de la formula orgánica para teñir con añil se recomienda por dos razones principales:

a. Mayor protección de la salud de los teñidores y teñidoras, ya que la formula orgánica tiene de base productos naturales no tóxicos.

b. Mayor protección al medio ambiente, ya que por su base natural no toxica, la formula orgánica no contamina el medio ambiente.

3. Aunque teñir con añil usando una formula orgánica no representa mayor riesgo para la salud, se recomienda el uso de equipos personales de protección mientras se tiñe 0 se manipulan productos recién teñidos, a saber: lentes de protección, mascarillas, guantes de nitrilo 0 de látex y gabacha. No se tiene conocimiento, al momento de escribir este reporte, de efectos negativos en la salud por exposiciones prolongadas con formulados orgánicos con añil en la piel o de la respiración continua de los baños de tintura en los pulmones 0 tracto respiratorio.
4. Determinar si la tela a teñir es $\mathbf{1 0 0 \%}$ algodón, utilizando uno de los métodos empíricos para identificación de fibra sugeridos: método de absorción de agua y método de quemado.

5. Lavar todas las fibras o telas antes de teñir con añil. Mantenerlas completamente mojadas antes de teñir. Poner las madejas en un aro para que no se enreden; las telas se pueden sumergir directamente.

6. Para teñir con añil efectivamente se deben controlar principalmente tres variables: la temperatura, el $\mathrm{pH}$ y el color (reducción de oxigeno) del baño.

7. Para evitar las manchas, mover a un lado la nata del añil de la superficie del baño justo antes de teñir, y antes de quitar las muestras de la solución. Sumergir las fibras o materiales en el baño de añil hasta que estén completamente cubiertas. Los materiales deben permanecer completamente debajo de la superficie del agua durante todo el proceso de teñir. Lentamente mover las madejas 0 tela debajo de la superficie para que se tiñan de forma pareja. Darle vuelta a las muestras lenta y cuidadosamente para evitar introducir oxígeno al baño de tinte.

8. Durante el proceso entero de teñir con añil, asegurarse de mantener una temperatura constante. Los valores dados son solamente una guía:

Lana, alpaca y seda: $50-55^{\circ} \mathrm{C}$

Algodón y yute: $\quad 30-35^{\circ} \mathrm{C}$ 
9. El tiempo de permanencia que una muestra debe estar sumergida en la tina de añil depende de la fibra que se esté tiñendo. A continuación están los tiempos máximos requeridos de sumergir, basados por tipo de fibra:

Lana, alpaca y seda: 10 minutos

Algodón y yute: 5 minutos

Sin importar el tipo de fibra, la mejor forma de teñir un azul añil oscuro es incrementando el color con una serie de inmersiones sucesivas. No sumergirla prenda por una hora de una vez, esperando que el color sea permanente; el azul teñido de esta forma se desteñirá constantemente al frotar o lavar. Si se desea un color claro, es mejor sumergir la prenda dos o tres veces por 2 ó 3 minutos en un baño de teñido menos concentrado.

10. Lenta y suavemente sacar la fibra u otro material natural del baño de tinte, tratando de no introducirle aire. Cuando se saque del baño de añil, la fibra tendrá un color amarillo. Al hacer contacto con el aire, cambiará de color a verde y después azul. Dejar los materiales airearse en la sombra por un tiempo mínimo de 20 a 30 minutos para facilitar el cambio de color. Desplegar y rotar la fibra o estambre para que el aire pueda penetrar todas las superficies.

11 La fibra se puede remojar y airear varias veces. Exprimir el tinte sobrante antes de re-sumergir. Repetir este proceso hasta que se consiga el tono de azul que se desea. Recordar teñir dos o tres tonos más oscuros de lo que se quiere porque el color se hará más claro después del lavado y el secado.

12. La recarga del baño se hace añadiendo $200 \mathrm{ml}$ (un cuarto de taza) de extracto después de cada remojada hasta que el baño de tinte esté concentrado. Esto se puede checar fácilmente no añadiendo extracto entre cada remojada y notando el cambio de color que resulta. Si el color no oscurece mucho después de la inmersión, añada más extracto para la próxima. $\mathrm{Si}$ el color oscurece, el baño tiene suficiente tinte.

13. Para mejor resultado, dejar la fibra airearse 24horas después de la última inmersión y antes de lavarla.

14. No utilizar sal común ( $\mathrm{NaCl})$ en el baño de enjuague porque el colorante añil es un colorante tina y no un colorante directo, por lo que no requiere de fijador, como lo es la sal común. Además, el agregar sal común al baño de enjuague hace que este se transforme en un medio alcalino que puede causar una disminución en la fijación del colorante.

15. Para mejorar la fijación del colorante en la fibra, el proceso puede terminarse con dos pasos: neutralizar y lavar.

16. Después de teñir con añil, neutralizar las muestras en un baño de tanino (10 bolsitas de té por cada $\mathrm{kg}$ de algodón, yute, etc.) o de un ácido (media taza de vinagre por kg de lana, alpaca y seda). Remojar las fibras en agua tibia $\left(40^{\circ} \mathrm{C}\right)$ 
por 15 minutos hasta que el agua de enjuague tenga un $\mathrm{pH}$ entre 5.5 y 7 .

17. Lavar en agua muy caliente $\left(77^{\circ} \mathrm{C}\right)$ con un jabón neutro de base vegetal $(\mathrm{pH}$ de 7) por 20 minutos. Frecuentemente se requieren dos o tres lavadas de agua caliente - con agua limpia - para quitar el exceso de añil. Terminar con una serie de enjuagues en agua tibia (sin jabón) hasta que el agua pase transparente y el color no se destiña. Reutilice esta agua de enjuague después de teñir varias veces con añil hasta que el agua no le sea efectiva. Es importante conservar agua cuando sea posible.

\section{Reconocimientos}

Los autores desean agradecer la invaluable colaboración y asesoría que Karina B. Martínez, Rosa María Guerrero y Xenia I. Pereira brindaron para el éxito de esta investigación.

\section{Notas y referencias}

1 José A. González, Centro de Investigación en Ciencias, Universidad Francisco Gavidia, San Salvador, El Salvador.

2 Patricia G. Bernal y Delmi Linares, consultoras independientes, San Salvador, El Salvador.

3 Elizabeth M. Crown, Departamento de Ecología Humana, Universidad de Alberta, Ciudad de Edmonton, Alberta, Canadá.

4 El mordiente es una sustancia empleada en tintorería que sirve para fijar los colores en los productos textiles. La función del mordiente es favorecer la fijación del colorante en las fibras textiles.
5 El pH (potencial de hidrógeno) es una medida de la acidez o alcalinidad de una solución.

6 El valor pK es la medición logarítmica de la constante de disociación acida. Entre más grande es el valor de pK, menor es el valor de la disociación.

7 Desprotonación es un término químico que se refiere a la remoción de un catión hidrógeno $(\mathrm{H}+)$ de una molécula, formando la respectiva base conjugada.

8 La fermentación bioquímica es un proceso metabólico mediante el cual los electrones liberados de los nutrientes son en última instancia transferidos a moléculas obtenidas por la ruptura de esos mismos nutrientes.

9 Una inmersión está compuesta de 2 a 3 minutos de permanencia dentro del baño con movimientos lentos de la tela en la solución, exprimiendo la muestra para remover exceso de colorante sin provocar burbujas de aire al hacerlo, y una exposición al aire por otros 2 a 3 minutos para oxidación.

10 Se ideó un método empírico para evaluar la solidez al frotado: tiras de tela de algodón $100 \%$ de $1 \mathrm{~cm}$ de ancho fueron frotadas tres veces contra la superficie de la tela teñida, guiadas con el dedo índice y aplicando una presión moderada. Para la prueba en húmedo se depositó una gota de agua de chorro en la tira de tela antes de proceder a frotar la muestra teñida.

11 Enjuague hecho a temperatura ambiente con agua del chorro corriendo hasta que no se notaba sangrado de colorante de la tela.

12 Levadura de uso casero, vendida comercialmente. 
13 Secado parcial significa el secar las muestras por aproximadamente dos horas, y estando húmeda todavía, se aplica el enjuague.

14 Secado total significa que las muestras fueron secadas totalmente antes de ser enjuagadas.

15 Cantidad de colorante que se pierde durante el enjuague con respecto al peso de la muestra teñida sin enjuague.

16 Cantidad de colorante que permanece en la tela después del teñido y enjuague.

17 Con un porcentaje de Índigotina de por lo menos $40 \%$

18 Se entiende por formulado químico aquel que utiliza hidrosulfito de sodio y soda caustica como agentes reductores y alcalinos, respectivamente.

\section{Bibliografía}

Balfour-Paul, J. (2000). Índigo. London, UK: British Museum Press.

Bamford, C.H.; Collins, J.R. (1950). Kinetic studies on carbohydrates in alkaline conditions. I. Thekinetics of theautoxidation of glucose (Estudios cinéticos de hidratos de carbono en condiciones alcalinas. I. La cinética de la auto-oxidación de la glucosa). Proceedings of the Royal Society of London Series AMathematical Physical and Engineering Sciences, 204, 62-84.

Blackburn, R.S.; Harvey, A. (2004).Green ChemistryMethods in SulfurDyeing: Application of VariousReducing D-Sugars and Analysis of thelmportance of OptimumRedoxPotential (Métodos de Química Verde en el teñido sulfuroso: aplicación de diversas azúcares reductoras tipo D y análisis de la importancia del potencial Redoxoptima). EnvironmentalScienceTechnology, 38, 40344039.

Bonavente, T. (1988). Historia de los Indios de la Nueva España. Madrid, España: Alianza Editorial.

Božič, M.; Kokol, V. (2008). Ecologicalalternativestothereduction and oxidationprocesses in dyeingwithvat and sulphurdyes (Alternativas ecológicas de los procesos de reducción y oxidación en el teñido con colorantes tina y sulfurosos). Dyes Pigments, 76, 299-309.

Clark, R.J.H.; Cooksey, C.J .; Daniels, M.A.M.; Withnall, R. (1993). Índigo, woad, and Tyrianpurple: Important vat dyes from antiquity to present (Añil, woad y moradoTyrian: Importantescolorantestina de la antiguedad al momento actual). Endeavour, 17, 191-199.

Chavan, R.B. (2001). Environmentfriendlydyeing processesforcotton

(Procesos de teñido amigables al medio ambiente para algodón). IndianJ ournal of Fibre Textiles, 26, 93-100.

Etters, J.N. (1995). Advances in índigo dyeing: Implicationsforthedyers,

apparelmanufacturer and environment (Avances en teñido del añil: Implicaciones para el teñidor, productor de vestuario y el medio ambiente). TextileChemist and Colorist, 27 (2), 17-22.

Etters, J.N. (1993). Índigo dyeing of cottondenimyarn:

correlatingtheorywithpractice (Teñido con añil de hilos de algodón para mezclilla: correlacionando teoría con la práctica). Journal of the Society of Dyers Colourists, $109,251-255$. 
Etters, J.N. Hou, M. (1991).Equilibriumsorptionisotherms of índigo oncottondenimyarn: effect of $\mathrm{pH}$ (Isotermas de equilibrio de sorción de añil en el hilo de algodón para mezclilla: Efecto del pH). Textile Research Journal, 61, 773776.

Ferreira, E.S.B., Hulme A. N., McNab H., \&Quye A. (2004).Los componentes naturales de los colorantes textiles históricos. Chemical Society Reviews, 33 (6), 329-36.

Ferrier, M.J.; Collins, P.M. (1972).Monosaccharide chemistry (Química de mono-sacáridos).Harmondsworth, UK: PenguinBooks.

Fester, G.A. (1955). Algunos colorantes de alguna antigua civilización suramericana. Revista del Museo Nacional de Antropología y Arqueología, 2 (1).

Ghanem, M.A.; Compton, R.G.; Coles, B.A.; Canals, A.; Vuorema, A.; John, P.; Marken, F. (2005). Microwaveactivation of the electro-oxidation of glucose in alkaline media (Activación por microondas de la oxidación eléctrica de la glucosa en un medio alcalino). PhysicalChemistry, 7, 35523559.

Gilbert, K.G., Cooke. D.T. (2001). Colorantes de plantas: Usados pasados, entendimiento $y$ potencial contemporáneo. Plant Growth Regulation, 34, 57-69.

Hurry J.B. (1930). The Woad Plant and its Dye (La planta de woad y sucolorante). London, UK: Oxford University Press.

Johnson, A. (1989). The theory of coloration of textiles (Second edition) (La teoría de teñido de textiles).Bradford, UK: Society of Dyers and Colourists.
Kobo, A. (Mayo de 2011).Azul japonés profundo y rico (Deep, RichJapan Blue). KyotoThisMonth, 24 (5). Disponible en http://www.kyotoguide.com/ver2/thismont h/aizome.html (Consulta: 26/08/2011).

Kriger, C. E. \&Connah, G. (2006). Vestiduras en la Historia de África Occidental (Cloth in West AfricanHistory). Rowman Altamira. ISBN 0-7591-0422-0

Leonowens, S. (2007). Desarrollo de una Línea de Mantelería Tejida con Hilos Teñidos en Añil Orgánico para Pro Teje. Tesis para completar estudios de Licenciatura en Diseño Industrial del Vestuario. Ciudad de Guatemala, Guatemala: Universidad del Istmo.

Lowengard, S. (2006). Azul por excelencia en el Siglo XVIII. En "La Creación del Color en la Europa del Siglo XVIII." West Sussex, UK: Columbia UniversityPress.

Martínez, K. \& Sierra, C.S. (2009). Diagnóstico del proceso de teñido con añil y una propuesta de teñido orgánico. Trabajo de graduación para optar al grado de Ingeniero Químico. San Salvador, El Salvador: Universidad Centroamericana "José Simeón Cañas."

Minami, Y.; Kanafuji, T.; Miura, K. (1996). Purification and characterization of a $\beta$ glucosidasefrompolygonumtinctorium, whichcatalyzespreferentiallythehydrolysis of indicant (Purificación y caracterización de un $\beta$-glucosidasa del polygonumtinctorium, que cataliza preferentemente la hidrólisis del indican). Bioscience Biotechnology and Biochemistry, 60, 147-149.

Padden, A.N.; Dillon, V.M.; John, P.; Edomnds, J.; Collins, M.D.; Alvarez, N. (1998). Clostridiumused in 
mediaevaldyeing (Clostridium utilizado en el teñido medieval). Nature, 396, 225.

Perkin, A.G.; Bloxam, W.P. ( 1907).Indican. Part I Transactions (Indican. Parte I Transacciones).journal of the Chemistry Society, 91, 1715-1728.

Rivera, R.A., Martínez, A.l. \&Merlos, E. (2007).Lecciones para reactivar agroindustrias rurales: La experiencia del añil en El Salvador. San Salvador, El Salvador: Instituto Interamericano de Cooperación para la Agricultura (I.I.C.A.).

Roessler, A.; Crettenand, D. (2004). Directelectrochemicalreduction of vatdyes in a fixedbed of graphite granules (Reducción electroquímica directa de colorantes tina en una cama de gránulos de grafito). Dyes and Pigments, 63, 29-37.

Roquero, A. (1995). Colores y colorantes de América. Anales del Museo de América, 3, 145-160.
Sahagún, B. (1985). Historia General de las Cosas de la Nueva España. M éxico: Editorial Porrúa.

Tamura, S. (1994). Colorantes Naturales. Japón.

Russell, G.A.; Kaupp, G. (1969).Oxidation of Carbanions. IV. Oxidation of Indoxyl to Índigo in Basic Solution (La oxidación de los carbaniones. IV. La oxidación de indoxyl a añil en una solución básica). Journal of the American ChemistrySociety, 91, 38513859.

Vuorema, A. (2008). Reducción y métodos de análisis del añil. Tesis para completar estudios de Maestría en Ciencias. Turko, Finlandia: Universidad de Turku.

Wipplinger, M. (1996). Tintes naturales para artesanos de las Américas. Washington, DC: Organización de los Estados Americanos (O.E.A.). 
